\title{
Brown Adipose Tissue: Research Milestones of a Potential Player in Human Energy Balance and Obesity
}

Author

Affiliation
B. Zafrir

Department of Cardiovascular Medicine, Lady Davis Carmel Medical Center, and the Ruth and Bruce Rappaport School of Medicine, Technion-Israel Institute of Technology, Haifa, Israel
Key words

- brown adipose tissue

- thermogenesis

- energy balance

obesity received 21.03.2013

accepted 21.05.2013

Bibliography DOI http://dx.doi.org/ 10.1055/s-0033-1348264 Published online:

June 26, 2013

Horm Metab Res 2013;

45: 774-785

(c) Georg Thieme Verlag KG Stuttgart · New York ISSN 0018-5043

Correspondence

\section{B. Zafrir, MD}

Cardiovascular Department Lady Davis Carmel Medical Center

7 Michal St.

Haifa

Israel

Tel.: + 972/48/250 285

Fax: + 972/99/560 390

barakzmd@gmail.com

\section{Abstract}

$\nabla$

Obesity and diabetes mellitus are worldwide epidemics driven by the disruption in energy balance. In recent years, it was discovered that functional brown adipose tissue (BAT), once thought to exist mainly in infants, is present in adults, and can be detected during cold stimulation, and is associated with decreased adiposity. Brown fat pads were shown to be highly vascularized and metabolically active and on stimulation, they caused enhanced energy expenditure and increased glucose and fatty acid uptake. These observations drew attention to the possibility that nonshivering thermogenesis mediated by activation of BAT might be important in human energy balance and a potential tool to counter obesity. Recent investigations have revealed significant advances in the understanding of the role of BAT-mediated thermogenesis,

\section{Introduction}

$\nabla$

Obesity is a major public health problem and a worldwide epidemic contributing to the development of dyslipidemia, type 2 diabetes, and cardiovascular diseases [1]. It often results from a derangement in energy balance, impairing the equilibrium between energy intake and expenditure. The treatment of patients with obesity requires significant efforts in lifestyle modifications, which are often difficult to implement and only transiently successful. Other approaches, such as drug treatments and bariatric surgery, are accompanied by risks and are suitable for limited groups of the obesogenic population. Hence, considerable efforts are aimed at developing novel therapeutic tools to aid in countering obesity. A possible approach that recently drew interest in the medical scientific community was to increase energy expenditure through the stimulation of brown adipose tissue (BAT). BAT is uncovering essential knowledge on the origin, differentiation, activation, and regulation of BAT in both murine models and humans. In addition to classic BAT depots, transformation of white adipocytes into brown-like adipocytes, and the development of "beige" cells from distinct precursors, were demonstrated in different animal models and resulted in increased thermogenic activity. Several transcription factors, activating proteins, and hormones are increasingly identified as regulating the development and function of both brown-like adipocytes and classic brown fat pads. This review will summarize the evolution of research on BAT in humans, in light of the renewed scientific interest and growing body of evidence showing that recruitment and activation of BAT and browning of white adipose tissue can affect energy expenditure and may be a future feasible target in the treatment of metabolic diseases. a unique adipose tissue; its main function is to generate heat by dissipating chemical energy. It has largely been investigated in the past for its role in small mammals, allowing nonshivering thermogenesis in response to low temperatures, and was thought to be present only in newborns and small children among humans [2]. Apart from the defense against cold, BAT thermogenesis was demonstrated in multiple studies in mammals to increase energy expenditure, affecting excess of lipids and accumulation of fat. The activation of BAT is mainly under the control of the sympathetic nervous system, in which the adrenergic response triggers energy uptake of fatty acids and carbohydrates into BAT and stimulates thermogenic activity. This activity is mediated, in particular, by the hypothalamus and is regulated by a wide range of transcriptional factors and regulators. In recent years, there has been growing evidence that BAT is active in not only small mammals and newborns but also 
adult humans. Imaging modalities such as ${ }^{18} \mathrm{~F}$-fluorodeoxyglucose positron emission tomography/computed tomography (FDG-PET/CT) enabled recognition and measurement of the mass and activity of BAT in humans, and recent investigations have enriched our understanding of the prevalence, clinical correlations, activators, and regulatory systems of BAT. These findings raised the possibility that BAT is metabolically active in adults and is a significant tissue that may be potentially recruited to aid in therapeutic efforts addressing excess fat accumulation, dyslipidemia, and metabolic diseases. Obstacles to achieve these goals include the low amount of BAT in humans compared with rodents, especially in obese and older individuals, and strategies to increase the mass and function of BAT, thereby sustaining its activity.

The aim of this article is to review broad themes of recent research on BAT and its influence on energy balance, obesity, and metabolic diseases. The evolution of research on BAT in humans will be reviewed, with a focus on the up-to-date evidence for the development, stimulation, regulation, and transcriptional control of BAT thermogenesis. Furthermore, recent investigations linking BAT and cardiometabolic activity will be highlighted, including the role of natriuretic peptides (NPs), epicardial fat, and lipoprotein metabolism.

\section{The Obesity Epidemic and Energy Balance}

Obesity has become a major global public health problem in recent decades, and it has reached epidemic proportions in not only high-income countries but also most middle-income societies. Data from the World Health Organization indicate that the number of people with obesity has increased more than 2-fold worldwide since 1980 and $65 \%$ of the world's population today lives in countries where overweight and obesity are responsible for more deaths than underweight [1]. Obesity affects approximately one-third of the US adult population, with an additional similar proportion of the population known to be overweight [3]. It is also an impending problem for young individuals; more than 40 million children younger than 5 years of age were defined as overweight by the World Health Organization in 2010 and are at an increased risk for cardiovascular diseases in the future as adults because of childhood overweight [4]. Obesity is now a leading cause of morbidity, disability, and premature mortality, contributing to various medical comorbidities and complications. Adiposopathy ("sick fat") results in endocrine and immune derangements and contributes to cardiovascular diseases both directly and indirectly through worsening of major risk factors for cardiovascular disease [5]. It is correlated with hypertension, insulin resistance and diabetes mellitus, dyslipidemia, and physical inactivity and is associated with a significant increase in the number of cardiovascular events and the risk of mortality.

Energy balance, simplistically, is composed of energy intake, energy expenditure, and energy storage. Obesity often results from an imbalance between energy intake (food eaten) and expenditure, which is composed of the basal metabolic rate (from rest and obligatory energy) and physical work including physical activity and nonexercise adaptive thermogenesis [6,7]. The major environmental factors that contribute to imbalance in this equation are reduced physical activity in the sedentary population and increased energy intake from high-calorie foods and drinks.
Previous reports support the hypothesis that increased food intake is the main cause of obesity in modern populations, owing to an increased supply of cheap, palatable, high-caloric energy foods, which have become more accessible in recent decades and thereby encouraging food consumption [8]. The decline in daily life physical activities over the past century has been substantial, deriving from industrialization, urbanization, development of motorized transportation, etc., and resulting in marked changes in daily lifestyle. Physical activity can be divided into occupational (work-related) and leisure-time activities. Although leisure-time activities partially maintain their importance in developed societies, in the past decades, there has been a progressive decline in the percentage of individuals employed in occupations that require intense physical activity. Even though physical activity reduces the likelihood of developing obesity, there is debate concerning the extent of the impact of exercise on the obesity epidemic $[9,10]$.

The human body possesses several processes for dynamic physiological adaptations to alteration in body weight. For example, gain of weight results in increased energy expenditure due to a higher rest metabolic rate and eventually, a further increase in energy intake to sustain the increased weight [11]. All the components of energy balance interact with each another, and a deviation in energy balance results in compensatory changes of its various components. Food restriction results in a compensatory reduction in the resting metabolic rate and a decrease in energy expenditure, parallel to increased hunger, thus reducing the success of long-term maintenance of weight loss [12,13]. The concept of "high-energy flux" suggests that human physiology is biased toward achieving efficient energy balance at a high level of energy intake and expenditure, which is achieved in a sedentary environment by weight gain instead of a high level of physical activity. Thus, optimal energy balance may be easier to achieve at high-energy throughput by increasing physical activity in the population and entering the "regulated zone" of energy balance [14].

Other environmental and circumstantial factors might have influenced the obesity epidemic in recent decades. Factors that have been suggested to promote obesity are changes in smoking habits, sleep disorders with reduced sleeping periods, and environmental contaminants. Furthermore, genetic predispositions, gene-environment interactions, and epigenetic modifications may contribute to mechanisms regulating obesity.

An important environmental factor that may have a role in energy balance and obesity is reduced exposure to ambient temperature variability in daily life, mainly reduced exposure to seasonal cold [15]. This reduced exposure occurs as a result of the wide-scale accessibility to cheap and efficient energy sources, exposure to air conditioning and central heating, reduction in outdoor activities, and an increase in temperature-controlled environments and consequently, increased time spent indoors. This "thermal comfort" zone has been observed in recent decades in developed countries, manifesting as a reduction in seasonal exposure to mild cold and increase in domestic winter temperatures. This thermal comfort zone is suggested to negatively affect energy expenditure and contribute to the rise in obesity prevalence in the population by reducing thermogenic capacity and the need for physiological thermogenesis [15].

Overall, long-term dysregulation of energy balance is a key component of the obesity epidemic. However, influencing energy balance by intensive lifestyle modifications in obese individuals is not easy to implement in our obesogenic environment. Caloric 
restriction is accompanied by an unpleasant hunger sensation and compensations leading to a reduced basal metabolic rate and reduced physical activity. Moreover, it should be noted that drugs suppressing appetite were partially withdrawn from the market because of severe adverse effects and are often not tolerated because of safety issues and potential side effects. A combination of caloric restriction and structured exercise may lead to more effective weight loss [16]. However, intense physical activity is often difficult for obese individuals, and it is suggested that small changes in an individual's lifestyle may have only a minor effect on weight loss and the prevention of obesity [17]. Because of the limited efficacy of medications and behavioral interventions, bariatric surgery techniques have increased substantially in recent years and provide a viable therapeutic option for severely obese patients with serious comorbidities. Bariatric surgery has been shown to improve metabolic dysfunction and decrease inflammatory cytokine levels. In addition, it was recently demonstrated to be associated with a reduced number of long-term cardiovascular events in obese adults [18] and contribute to better glycemic control in obese diabetic patients $[19,20]$. However, these procedures are invasive, have potential perioperative and long-term complications, and are currently a viable therapeutic option for a relatively small number of patients with morbid obesity and severe comorbidities. Therefore, methods to increase energy expenditure are still needed in order to provide other viable therapeutic options for patients with obesity and metabolic complications. Such therapies will further facilitate the positive effects of lifestyle changes, translating into weight reduction and improved cardiometabolic health. The unique features of BAT, enabling removal of a large amount of lipids from the circulation to activate thermogenesis, produce heat and affect energy expenditure, mark it as a potential therapeutic target in obese subjects.

\section{Characteristics and Evolutionary Considerations of Brown and White Adipocytes}

$\nabla$

Adipose tissue is composed of white and brown adipocytes, which are able to accumulate lipids in droplets intracellularly. White adipose tissue (WAT) is an energy-storing tissue that has evolutionarily enabled humans to survive for longer periods between meals, storing energy mainly as triglycerides and releasing fatty acids during fasting periods. WAT comprises the majority of adipose tissue in the human body, and in recent decades, when food has been cheap and widely available, it has contributed to obesity worldwide. Morphologically, white adipocytes have few mitochondria; they are composed of a peripherally located nucleus and a large single, spherical, lipid vacuole that functions as a storage droplet. It can increase in size and expand its volume by several times. WAT has endocrine activity, secreting hormones such as leptin and adiponectin, and is involved in the regulation of insulin sensitivity.

BAT consists of brown adipocytes, characterized by multiple, small, multilocular lipid droplets with a central nucleus and a high number of mitochondria, thus differing morphologically from WAT. BAT is highly vascularized tissue innervated by sympathetic nerve fibers. The mitochondria of BAT are unique in expressing uncoupling protein 1 (UCP1) in the inner mitochondrial membrane. This protein, when activated, separates (uncouples) electron transport in the respiratory chain (substrate oxidation) from generation of adenosine triphosphate and thus releases the energy stored as heat. Expression of UCP1 converts chemical energy, which originates mainly from fatty acids, into thermal energy, generating heat and resulting in thermogenesis. UCP1 is characteristically present in BAT and is not expressed in regular WAT.

BAT is highly present and active in newborns. Its evolutionary function is to generate heat for the newborn's body when no other ways of producing heat, such as skeletal muscle shivering thermogenesis, have yet developed. This nonshivering thermogenic role of BAT, which maintains the core temperature during exposure to cold, is also seen in small mammals. Children have a high amount of active BAT, but the amount and activity of BAT declines rapidly after puberty. In adults, BAT is concentrated in the trunk, and the largest regions of BAT mass are found in humans in the supraclavicular and neck regions, which evolutionarily might have been important in providing warm blood to the brain. A smaller amount of BAT is found in humans around the spinal cord and the paravertebral and peri-aortic regions.

\section{BAT in Adult Humans \\ $\nabla$}

Previous literature has indicated that BAT may have a potential role in regulation of not only body temperature during cold exposure but also body weight and lipid metabolism. The physiology and activity of BAT have been scientifically investigated, mainly in rodents, in numerous studies in recent decades. These studies have confirmed the presence of BAT and shown the benefits of activating BAT for regulation of body weight. Various examples from animal studies are as follows: "cafeteria-fed" animals had increased mass and function of BAT; surgical excision of BAT in mice resulted in increased body weight; overexpression of transgenic mice with UCP1 protected against obesity; and adrenergic stimulation of the beta3-adrenoreceptor resulted in appearance of BAT in WAT regions, accompanied by increased expression of UCP1 and reduction in body weight [21].

BAT was initially noticed in humans several decades ago. The function of BAT in infants was described in the 1960s, and the question of the clinical significance of BAT in adults was then raised in the 1970s [22,23]. Interestingly, a highly quoted work from Finland in 1981 demonstrated that outdoor workers had BAT surrounding their neck arteries much more often than indoor workers, suggesting that working in the cold can retain BAT [24]. Pheochromocytoma, a catecholamine-secreting tumor of the adrenal medulla, was shown to be associated with activation of BAT in the 1980s; this finding suggested that human BAT has the potential for thermogenic activity and may contribute to weight loss through the high level of catecholamines activating BAT [25]. Catecholamines can induce weight loss through different pathways. However, it has been shown that FDG-PET uptake in BAT was no longer apparent after resection of a pheochromocytoma tumor [26]. Indeed, a recent study correlated elevated plasma levels of metanephrine and BAT activity, providing evidence that catecholamines stimulate BAT thermogenesis in the presence of an adrenal tumor and are negatively associated with adiposity [27]. However, BAT has been generally considered to be nonfunctional with no significant physiological relevance in healthy adult humans until recent years.

\section{The renewed interest in BAT in humans}

The renewed interest in BAT occurred as a result of an incidental finding. In the 1990s, FDG-PET scans were performed by radiolo- 
gists to detect increased glucose uptake in tumors and identify metastatic progression. During these scans in patients with cancer, radiologists noticed a repeated pattern of bilateral symmetrical glucose uptake in the upper chest and neck regions, initially ascribed to artifacts or muscle uptake because of their symmetrical distribution [28]. After combining FDG tomography with $\mathrm{CT}$, it became possible to determine the composition of this symmetrical uptake and this mass was identified as adipose tissue. In 2002, using hybrid PET/CT imaging, Hany and colleagues elegantly suggested that the symmetrical FDG uptake was related to adipose tissue and probably represented activated BAT during the increased sympathetic activity induced by the cold stress in the imaging room [29]. Several other reports discussing FDG-PET uptake in BAT in adult humans were published soon after, mainly in nuclear medicine journals $[30,31]$. Surprisingly, it took another several years until Nedergaard and colleagues raised awareness of the "unexpected evidence for active BAT in adult humans" and its potential to be of metabolic significance in human physiology and in the efforts to combat obesity [32]. Still, because of the retrospective nature of the FDG-PET studies, the presence of active BAT in humans was believed to be apparent in only a small percentage of adults.

This notion changed after the results of parallel prospective studies from several independent working groups were presented in 2009. Cypess and colleagues retrospectively analyzed FDG-PET/CT scans performed in 1972 patients for various diagnostic reasons [33]. Concentrations of depots of BAT were identified in regions of the anterior neck and thorax. Positive scans were seen in $7.5 \%$ of women and $3 \%$ of men (this low percentage was because the studies were performed in a nonstimulated state and PET/CT identifies uptake mainly in tissues with increased metabolic activity). The probability of detection of BAT was inversely correlated with age, outdoor temperature, use of a beta-blocker, and body mass index (BMI) in the older patients. Additionally, UCP1 activity was identified in 33 biopsy specimens from the same cervical and supraclavicular regions in which BAT was observed on PET/CT.

At the same time, prospective studies were conducted to intentionally examine BAT activity in cold stressed subjects. Lichtenbelt et al. found BAT activity using FDG-PET/CT in 23 of 24 healthy men during mild exposure to cold $\left(15^{\circ} \mathrm{C}\right.$ for $2 \mathrm{~h}$ while ensuring that there was no cold-induced shivering thermogenesis by muscles) but not under thermoneutral conditions. This activity had negative correlation with BMI, suggesting that the reduced BAT activity in obese individuals may make it a target for the treatment of obesity [34]. Saito and colleagues also demonstrated that cold-induced uptake was observed on FDG-PET/ CT in 27 of 32 young healthy volunteers but in only 2 of 24 elderly subjects, with no detectable uptake in warm conditions. The BAT activity was inversely correlated with BMI and was higher during the winter months [35]. Another study performed at the same time examined histologic samples of adipose tissue from the neck of patients undergoing thyroid surgery [36]. UCP1 activity was found in one-third of the 35 patients, with evidence of BAT precursors. BAT had high sympathetic innervation and capillary density. Virtanen et al. additionally showed that exposure to cold increased FDG-PET/CT glucose uptake 15-fold in the supraclavicular area of 5 healthy volunteers [37]. Three of their subjects underwent tissue biopsies from areas corresponding to the glucose uptake, showing that these tissues express messenger RNA for markers of BAT and substantial levels of UCP1 pro- tein and cytochrome $c$ (a mitochondrial marker that is abundant in BAT).

Collectively, these studies in humans demonstrated the presence of BAT mass and activity in adults based on cold-induced glucose uptake tests and biopsies, showing variability (30$100 \%$ ) in study results based on age, BMI values, gender, and ambient temperature. However, these values were much greater than those of the earlier retrospective PET/CT studies, which reported a low prevalence of BAT in adult humans, varying from $2.5 \%$ to $8.5 \%$ of tested individuals because of thermoneutral noncold-induced conditions.

The next step was to confirm that BAT is indeed metabolically active in humans and contributes to cold-induced nonshivering thermogenesis. Researchers recently measured blood perfusion in BAT using a technique of intravenous injection of $\left[{ }^{15} \mathrm{O}^{1} \mathrm{H}_{2} \mathrm{O}\right.$ and a dynamic PET/CT emission scan. They found that cold activation of BAT leads to a greater than 2-fold increase in the perfusion rate of the tissue in parallel to elevated glucose uptake, reflecting the dense vascularity of this tissue and the increased oxygen requirement. Moreover, increased blood flow was associated with whole-body energy expenditure during cold exposure, indicating active thermogenesis [38]. Others have also shown that increased energy expenditure after exposure to cold in healthy volunteers is correlated to BAT activity quantified from FDG uptake [39].

Recently, Quellet and colleagues found that cold activation of BAT is associated with not only increased blood flow but also higher oxidative metabolism in the tissue [40]. This finding was confirmed by exposing healthy subjects to controlled cold and injecting a bolus of labeled radioactive acetate into their blood. The acetate is distributed to tissues according to their proportional blood flow. In this technique, loss of radioactivity from a tissue is an indication of active oxidative metabolism, and the radioactivity disappeared from BAT with a half-life of minutes in cold but not in warm subjects. Furthermore, nonesterified fatty acid uptake was quantified, showing increased uptake in coldactivated supraclavicular BAT in comparison to subcutaneous adipose tissue and resting skeletal muscles; these results suggest increased utilization of triglycerides as a source of energy for BAT thermogenesis.

A recent study using oxygen-15 PET imaging that evaluated the relationship between BAT oxidative metabolism and FDG uptake reported that despite elevated glucose uptake in BAT of adult humans, activated BAT did not contribute much to total energy expenditure [41]. The low activity of BAT depots in human subjects may reflect the low density of the brown adipocytes, and thus, the abundance of these cells would need to be increased in order to impact energy expenditure.

FDG-PET/CT is currently the imaging modality of choice for investigating BAT activity noninvasively. Recent developments in magnetic resonance imaging (MRI) may aid in the evaluation of BAT activity without exposure to ionizing radiation and with possibly better reproducibility and reduced cost. Recent studies have demonstrated the feasibility of measuring the volume and function of BAT in vivo using routine MRI sequences [42]. Other novel imaging techniques, including infrared thermography and new imaging tracers such as $4{ }^{18} \mathrm{~F}$-fluorobenzyltriphenylphosphonium ( $\left.{ }^{18} \mathrm{~F}-\mathrm{FBnTP}\right)$, are promising noninvasive tools for detection and monitoring of BAT in humans $[43,44]$. 


\section{BAT and its association with obesity in humans}

The central question is whether the presence, amount, or activity of BAT influences the tendency of an individual to become obese. It has previously been shown that BAT negatively correlates with the development of obesity in rodents. Mice that lack beta-adrenergic receptors or UCP1 protein have been shown to become obese $[45,46]$. Human studies in recent years verified these results, showing negative correlations between BAT activity and various measures of obesity, including BMI, percent body fat, and body fat content $[33-35,37,47,48]$. The decline of BAT activity with age was shown to be associated with accumulation of body fat [48], suggesting that BAT may contribute to adiposity in humans. Interestingly, in this study, adiposity increased with age in the BAT-negative group but not in the BAT-positive group, suggesting that BAT may protect against age-related accumulation of body fat. These results are supported by findings showing increased energy expenditure in subjects with higher BAT activity. A recent investigation of morbidly obese patients before and after weight loss induced by bariatric surgery reported an increase in the number of subjects with active BAT 1 year after surgery, as measured by FDG-PET/CT. After weight loss, the BATpositive subjects had significantly higher nonshivering thermogenesis compared with BAT-negative subjects, suggesting the recruitment of BAT in humans [49]. Obesity may confer insulation to the body, and thus, lower BAT activity may be an adaptive trait of obesity, whereas a decrease in insulation may be apparent because of the loss of subcutaneous adipose tissue after weight loss. However, it is arguable whether the lack of BAT is the cause or the consequence of the change in body composition.

\section{Other clinical correlations}

BAT is now confirmed to be present in adulthood. However, there is a clear decline in age-related function and mass of BAT in the majority of studies, and BAT is inversely associated with aging $[35,48,50-52]$. Several analyses have shown that BAT is more prevalent in women than in men [33,51-53]. This trend was seen also in studies of BAT in rodents [54]. This difference might be explained by the influence of the hormonal environment and differences in cold sensation between genders.

The association between BAT and environmental temperature is also well described. Activation of BAT is more frequent during the cooler seasons of the year [53], and seasonal variations and outdoor temperature appear to be related to detection of BAT by PET/CT scans $[33,35,55]$. In a recent review of 9 studies of BAT, it was found that the prevalence of activated BAT decreased by $1 \%$ for each increase of $5^{\circ} \mathrm{C}$ in average outdoor temperature and that the prevalence is lower in neutral ambient temperature and rare in tropical areas [56].

\section{Origins and Recruitment of BAT}

In the past, it was accepted that brown and white adipocytes had a common origin because of morphological analogy and the fact that both adipocytes store triglycerides in intracellular lipid droplets. However, it became apparent in recent years that BAT and WAT have different developmental origins. There are 2 independent pathways for the development of BAT. Classic BAT originates from muscle progenitor cells in the fetus, which leads to functional brown adipocyte cells that are located at typical brown fat pads. Muscles and brown fat cells have a common lin- eage, and both express myogenic factors such as myf5 [57]. It was demonstrated in rodents that brown fat cells derived from myf5 + cells were located at "classic" brown fat locations. In contrast, brown adipocytes induced by adrenergic stimuli were negative for the myf5 marker, and these cells were interspersed in WAT and might have been activated from dormant precursor cells [58]. Accordingly, the second origin of BAT is brown-like adipocytes that transiently emerge in traditional white fat depots, which are induced upon cold or adrenergic stimulation. These brown cells are typically called "recruitable" BAT and may be transdifferentiated from WAT ( $\bullet$ Fig. 1 ). This process is often termed development of "brite" (brown-in-white cells) or the cells are called "beige" cells [59-61].

Recent investigational experiments suggest that beige adipocytes are a separate subtype of adipocytes with a developmental origin, molecular characteristics and unique gene expression profile that distinguish them from WAT or classical BAT $[62,63]$. Although these cells are distinct from the classical brown adipocytes and have different expression pattern of various genes, they display the functional characteristics of brown adipocytes. These experiments, in different from the transdifferentiation theory, support the notion that beige cells progress directly from distinct precursor cells in the undifferentiated state into the brown adipocytelike appearance, without transition through a phase of being true white adipocytes $[62,63]$ ( 0 Fig. 1 ).

A recent report showed that beige cells are not a rare cell type in the subcutaneous tissue of mice. They have a very low level of UCP1 gene expression, comparable to that of WAT, in basal conditions. However, when activated by exposure to cold or betaadrenergic stimulation, these cells go through phenotypic transdifferentiation and morphological browning and express UCP1 at levels that are similar to those of classic BAT [63]. This research group further demonstrated that BAT previously identified in adult humans resembles murine beige cells more than classic brown fat. Recent data further indicate that human BAT may be primarily composed of beige/brite cells [64]. Increasing BAT recruitment and activation have potential therapeutic implications, and may be targets for pharmacological therapies for obesity and type 2 diabetes.

Investigators identified brown adipocyte stem cells which are CD34+in skeletal muscle, showing in adult humans the existence in skeletal muscle of a reservoir of progenitor cells with a high potential for brown adipogenic differentiation and UCP1 expression [65]. Human multipotent adipose-derived stem cells were also shown to be able to differentiate into "brite" (brownin-white) adipocytes [66]. Recent experiments established protocols to generate white and brown adipocytes from human pluripotent stem cells, showing distinct morphology, functional properties, and gene expression for each type of adipose cell. Moreover, transplantation of the cells into mice yielded ectopic fat pads with a morphology and function characteristic of primary BAT and WAT [67]. Nishio et al. recently suggested a highefficiency method to produce functional BAT from differentiation of human pluripotent stem cells. The generation of functional classical brown adipose pluripotent stem cells was accomplished without exogenous gene transfer, and resulted in lipid and glucose metabolic improvements [68].

Transplantation procedures for BAT progenitors may be a future therapeutic tool for the treatment of patients with obesity and metabolic derangements. A recent experiment in diabetic mice showed that subcutaneous transplants of embryonic BAT can cure type 1 diabetes, resulting in euglycemia, normalized glu- 


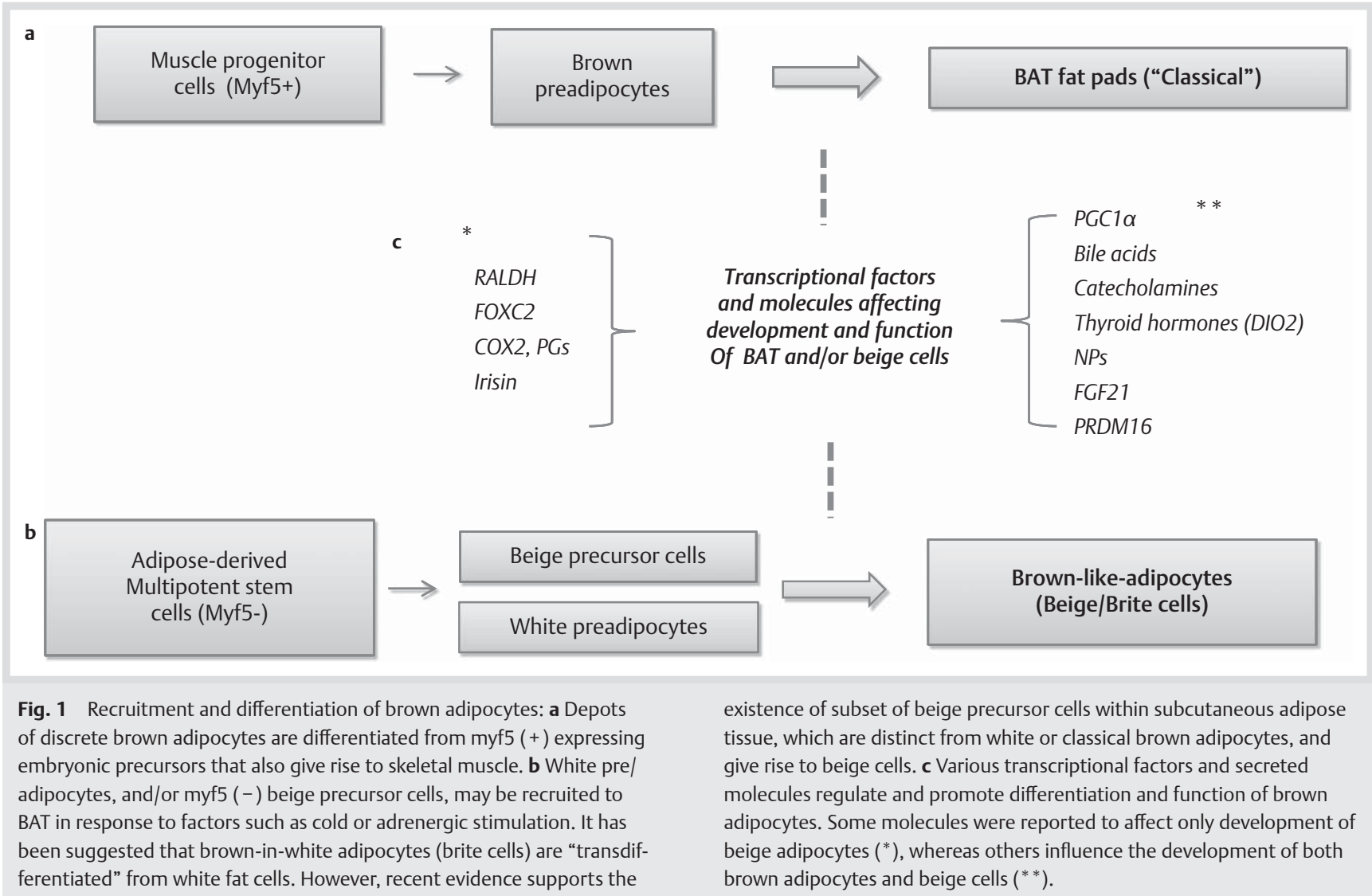

cose tolerance, reduced tissue inflammation, and reversal of clinical diabetic markers [69]. Researchers have also recently demonstrated that transplantation of BAT from donor mice into the visceral cavity of matched recipient mice, resulted in significantly decreased body weight and improved glucose metabolism and insulin sensitivity [70]. The mechanism for this effect involved BAT-derived IL-6. Transplantation of BAT from IL6knockout mice failed to significantly improve glucose homeostasis and insulin sensitivity.

\section{Stimulation and Activation of BAT \\ $\nabla$}

\section{Adaptive cold-induced nonshivering thermogenesis}

As explained in the previous text, exposure to cold stimulates nonshivering thermogenesis derived from the activity of UCP1 in BAT, a process that has been demonstrated and confirmed in numerous investigations in both small mammals and humans. Cold sensations signal neurons up to the pre-optic area of the hypothalamus, further activating the sympathetic nervous system to release norepinephrine, which induces UCP1 and BAT activity. This activity is also manifested in BAT during seasonal variations and increases during the winter months.

\section{Sympathetic nervous system}

Physiological regulation of BAT occurs via the sympathetic nervous system, mainly through activation of beta3-adrenergic receptors, which are expressed in brown adipocytes. The adrenergic stimulation increases intracellular levels of cyclic adenosine monophosphate (AMP), which activates protein kinase A, mediating transcriptional factors for the induction of thermogenic gene expression. As mentioned previously in this review, pheochromocytoma, a catecholamine-producing tumor of the adrenal gland, significantly increases the thermogenic activity of BAT and provides an example of the long-term sympathetic regulation favoring thermogenesis and reduced body weight. Drugs that increase sympathetic nerve activity, such as ephedrine and sibutramine, have also been targeted to increase thermogenesis, metabolic rate, and weight loss. However, widerange adrenergic drugs cause overstimulation of adrenergic receptors in the cardiovascular system, increasing the risk of vascular events. In addition, beta3-adrenergic agonists had an insufficient long-term effect on energy balance in human studies $[71,72]$. A recent study demonstrated consistent stimulation of BAT in healthy humans by exposure to cold, but not ephedrine, which even at doses with broad sympathetic activation was unable to appreciably affect BAT [73]. However, additional study using a higher dose $(2.5 \mathrm{mg} / \mathrm{kg})$ of acute oral administration of ephedrine, displayed activation of BAT in the majority of lean, but not obese humans, although the degree of activation was lower than that observed for cold exposure [74].

\section{Central control by the hypothalamus and the thyroid axis}

Changes in temperature are sensed by hypothalamic areas, which coordinate response through vasoactivity, and sympathetic nervous system regulation of BAT and thermogenesis. Recent studies imply that various hypothalamic peptides participate in the control of function and development of BAT. In addition, the hypothalamus responds to dynamic changes in metabolic state and nutrition through AMP-activated protein kinase (AMPK), which is an intracellular energy sensor that affects appetite and energy metabolism. It has also been suggested that hypothalamic inflammation and dysfunction are fac- 
tors contributing to the development of obesity through the effect on the control of BAT activity [75]. A recent review by Whittle et al. summarized the evidence on mechanisms of central regulation of thermogenesis [76].

Thyroid hormones are involved in the long-term regulation of energy balance and act coincidently with the sympathetic nervous system, enhancing adrenergic effects. Increasing the activity of the thyroid axis may lead to increased BAT activity. BAT expresses high levels of type 2 iodothyronine deiodinase, an enzyme that converts thyroxine (T4) to triiodothyronine (T3). Induction of type 2 iodothyronine deiodinase enhances local thyroid hormone signaling and energy expenditure during activation of BAT by exposure to cold. Recent data mark the role of thyroid hormones in the regulation of energy expenditure and BAT thermogenesis through the modulation of hypothalamic fat metabolism and AMPK activity [77]. Hyperthyroidism or central administration of T3 decreased the activity of AMPK, increasing sympathetic nervous system activity and upregulating thermogenic BAT markers. Inhibition of the lipogenic pathway in the hypothalamus nuclei or the thyroid hormone receptors prevented central nervous system-mediated activation of BAT and reversed the weight loss associated with hyperthyroidism. Thus, thyroid hormone-induced modulation of AMPK activity and lipid metabolism in the hypothalamus may be an important regulator of energy homeostasis.

\section{Diet-induced thermogenesis}

In rodents, feeding of a high-calorie diet in the presence of thermoneutral conditions results in increased BAT mass and thermogenic capacity, generating heat in response to cold but not through nonshivering thermogenesis [46]. This phenomenon was termed "diet-induced thermogenesis" in rodents [78]. Expression of UCP1 in BAT is increased in response to a high-fat diet in rodents, but the size effect is heterogeneous in different studies and seems to be independent of dietary fat content and duration of the feeding trial [79]. Enabling this mechanism in humans could be used for weight control and treatment of metabolic dysregulation. However, there is disagreement among studies concerning the possibility of diet-induced thermogenesis in humans [80]. A study comparing thermogenesis of human subjects exposed to both mild cold and overfeeding showed that the changes in energy expenditure during mild cold and overfeeding were significantly correlated [81]. Indirect evidence for involvement of BAT in diet-induced thermogenesis comes also from results from recent research in humans showing that insulin increases the metabolism of BAT, stimulating the rate of glucose uptake in BAT and suggesting that food that similarly elevates insulin levels may activate BAT as well [38]. However, to date, there are no direct intervention studies in humans showing a relation between overfeeding and BAT activity.

\section{Exercise}

Exercise is an effective way to maintain stable weight, aiding in the prevention of obesity. Physical activity results in an increase in activation of the sympathetic nervous system. However, previous data concerning the influence of exercise training on BAT recruitment and thermogenic activity displayed contradictory results. Nevertheless, recent studies suggest that exercise could be an effective stimulus to browning of WAT. A study evaluating the effects of exercise training in rats on a high-fat diet found that exercise increased mitochondrial number and brown adipocyte gene expression in WAT and BAT and enhanced the pop- ulation of brown adipocyte progenitor cells and brown adipogenesis [82]. In an additional investigation on the effect of exercise training on BAT in rats, browning of the visceral fat was observed by an apparently white-to-brown transdifferentiation, suggesting that exercise could be a physiological stimulus to counteract weight gain by an adrenergic-regulated brown recruitment of adipocytes [83]. Furthermore, a myokine called irisin, which is released to the circulation during exercise, was recently shown to stimulate UCP1 expression and brown fat-like development. Irisin was induced by exercise in both mice and humans [84]. We will discuss this in more detail in the next section.

\section{Physiology of BAT: Regulation, Differentiation, and Transcriptional Control $\nabla$}

Knowledge of the development and regulation of BAT has increased significantly in recent years, and a considerable number of transcriptional regulators, proteins, and hormones influencing the differentiation and function of BAT have been discovered, mostly in rodent investigations. Representative examples of milestone research developments in recent years are explained in the following text.

PGC-1 $\alpha$

PPAR $\gamma$ coactivator $1 \alpha$ (PGC- $1 \alpha)$ is a transcriptional coactivator that exerts its function by increasing the expression and activation of peroxisome proliferator-activated receptors (PPARs) and other transcriptional factors. PGC- $1 \alpha$ is expressed in BAT, especially during exposure to cold. Induced expression of PGC- $1 \alpha$ in WAT stimulates mitochondrial biogenesis and induces the expression of genes involved in oxidative phosphorylation and thermogenesis, such as UCP1. Mice deficient in PGC- $1 \alpha$ develop hypothermia during exposure to cold as a result of decreased nonshivering thermogenesis $[60,85]$, and it has been shown that beta-adrenergic stimulation cannot induce UCP1 in BAT that lack PGC- $1 \alpha$ activity [86]. A recent investigation found that loss of PGC- $1 \alpha$ in white fat resulted in reduced expression of thermogenic and mitochondrial genes, influencing regulation of glucose homeostasis and insulin resistance [87].

\section{PRDM16 and BMP}

The PR domain containing 16 (PRDM16) is a transcriptional regulator expressed at a high level in BAT. It has been shown to control a bidirectional cell fate switch between skeletal myoblasts and brown fat cells in mice. Loss of PRDM16 from brown fat precursors caused a loss of brown fat characteristics and promoted muscle differentiation. Conversely, ectopic expression of PRDM16 in myoblasts induced their differentiation into brown fat cells [58]. PPAR $\alpha$ induced PGC- $1 \alpha$ gene transcription in brown adipocytes through mechanisms involving PRDM16. In addition, activation of PPAR $\alpha$ in human WAT led to the appearance of brown adipocyte gene expression [88]. These results suggest that PPAR $\alpha$ acts as a key component of brown fat thermogenesis by regulating gene expression via induction of PGC- $1 \alpha$ and PRDM16.

Bone morphogenetic protein (BMP-7) is a member of the transforming growth factor $\beta$ family. It is secreted at an early phase of BAT differentiation and was shown to induce regulators of BAT such as PRDM16 and PGC1 $\alpha$ and the expression of the brown fat-defining protein UCP1 [89]. Recently, investigators described 
a role of BMP-8B in the direct regulation of thermogenesis, suggesting that this protein regulates energy balance by a coordinated activity in both the hypothalamus and mature BAT [90]. In addition, researchers have recently shown in a mouse model a role for BMP in the physiological cross-talk between constitutive and recruitable brown fat cells [91]. Genetic ablation of BMP receptors in BAT progenitor cells led to severe paucity of constitutive BAT, but compensatory increase in sympathetic input to WAT, promoting the formation of recruitable BAT within white fat depots. The purpose of this regulatory mechanism may be to restore total brown-fat mediated thermogenic capacity in the body and maintain normal temperature homeostasis.

\section{FOXC2}

FOXC2 is a member of the forkhead transcription factor family. Its overexpression in adipose tissue in mice led to browning of white fat pads and protected mice against diet-induced obesity and insulin resistance [92]. Enhanced expression of FOXC2 in adipocytes increases upregulation of genes encoding respiratory complexes and brown fat-related genes [93].

\section{FGF21}

Fibroblast growth factors (FGFs) have been implied in the physiology of BAT. Circulating FGF21 originates mostly from the liver and is a metabolic regulator of glucose and lipid homeostasis. Systemic administration of FGF21 in obese mice resulted in reduction in adiposity, increased energy expenditure, and improved glycemic control [94]. FGF21 is induced by cold exposure and adrenergic stimulation, and injection of FGF21 into mice induced genes involved in BAT thermogenesis [95]. A recent investigation reported that FGF21 has a physiological role in the thermogenic recruitment of WAT. Mice deficient in FGF21 displayed an impaired ability to adapt to long-term exposure to cold, with diminished browning of WAT. Adipose-derived FGF21 acted to increase expression of UCP1 and the appearance of brown-like adipocytes in subcutaneous WAT. Moreover, FGF21 enhanced PGC- $1 \alpha$ protein levels (a key regulatory protein in adipose tissue) independently of messenger RNA expression [96].

\section{VEGF}

Vascular endothelial growth factor (VEGF), a potent angiogenic factor, was found in the past to be expressed abundantly in the BAT of rodents when exposed to cold. The cold-induced increase in VEGF messenger RNA was abolished by sympathetic denervation but was elevated by administration of catecholamines [97]. Recently, researchers demonstrated that overexpression of VEGF resulted in increased blood vessel number and size in both WAT and BAT and protection against high-fat-diet-induced obesity. This increase was associated with increased thermogenesis and energy expenditure, increased insulin sensitivity and glucose tolerance, and an increased number of anti-inflammatory macrophages, suggesting that overexpression of VEGF in adipose tissue is a potential therapeutic strategy for the prevention of obesity and insulin resistance [98]. Another recent study showed that repression of VEGF-A induced development of brown-like adipocytes in WAT and upregulation of BAT-specific genes including PRDM16 and UCP-1 [99]. VEGF-A-repressed mice presented a lean phenotype and resistance to high-fat diet-induced body weight gain. The investigators suggested that repression of VEGF-A upregulated expression of VEGF-B and its downstream fatty acid transport proteins and that those relative levels of VEGF-A/VEGF-B might be important in energy metabolism.

\section{$\mathrm{COX} 2$}

Cyclooxygenase (COX) 2 is a rate-limiting enzyme in prostaglandin synthesis. COX2 activity and prostaglandin $E_{2}$ were reported to be involved in induction of UCP1 expression in inguinal white adipocytes but not in classic intercapsular BAT [100]. Coldinduced expression of UCP1 in WAT was repressed in COX2-deficient mice and by administration of a COX inhibitor(indomethacin), whereas injection of a prostaglandin $\mathrm{E}_{2}$ analogue induced expression of UCP1 in WAT. These findings support evidence that induction of UCP1 expression in WAT, but not in classic interscapular BAT, is dependent on COX activity, suggesting a role for COX in the control of energy balance and development of obesity. Other researchers have additionally shown that catecholamines induced COX2 activity in WAT and that overexpression of COX2 resulted in de novo BAT recruitment in WAT and increased systemic energy expenditure, which protected mice against high-fat diet-induced obesity [101].

\section{Myokines}

Myokines are peptides that are expressed and released by muscle fibers, enabling a secretory function of bioactive proteins. In recent years, it has been shown that myokines participate in endocrine "cross talk" with other tissues, including adipocytes [102]. Bostrom and colleagues recently identified in mice a new myokine hormone, irisin (a cleavage product of FNDC5), which is released to the circulation during exercise and acts on white adipose cells in culture and in vivo to stimulate UCP1 expression and brown fat-like development [84]. The same group recently showed that irisin preferentially activates beige fat cells [63].

The transcriptional coactivator PGC- $1 \alpha$ is expressed in muscle and is known to be increased during exercise and reduced with a sedentary lifestyle and diabetes. Increased levels of PGC- $1 \alpha$ in muscle stimulated an increase in the amount of irisin, acting on white adipocytes to stimulate expression of UCP1 and programming of brown fat-like development [84]. Irisin was induced by exercise in mice and humans and showed an increase in expression of UCP1 when injected in adenoviral particles to mice, resulting in an increase in energy expenditure and improvement in obesity and glucose homeostasis. These findings suggest that exercise, through the influence of irisin, has the capacity to turn on a phenotype similar to that of BAT and may have therapeutic implications for metabolic diseases.

\section{Retinoid metabolism in BAT}

Retinoids are vitamin A metabolites that stimulate various essential biological functions. They have been linked to an effect on obesity and diabetes [103]. A recent investigation showed a specific role for retinoid metabolism in BAT [104]. A deficiency of retinaldehyde dehydrogenase enzyme in mice (converting retinaldehyde to retinoic acid), which is predominantly expressed in WAT, induced a BATlike transcriptional program in WAT, promoting UCP1 and PGC- $1 \alpha$ expression, activating a thermogenic program, and limiting weight gain in obese mice, with improved glucose homeostasis.

\section{Macrophages and BAT}

Macrophage responses are broadly classified through 2 distinct activation programs, termed classical (M1; proinflammatory) and alternative (M2; anti-inflammatory). A transition from M2 to M1 predominance occurs in adiposity states, promotes metabolic inflammation and insulin resistance [105].

Recent data support macrophages as BAT regulators. Researchers reported that interlukin-4 (IL4), which is a direct inducer of 
M2 macrophages, stimulated a program of alternative macrophage activation required in adaptive thermogenesis [106]. In the absence of activated macrophages, impaired metabolic adaptations to cold were observed. Furthermore, administration of IL4 increased thermogenic gene expression and raised energy expenditure. Under cold stress conditions the alternatively activated macrophages (M2) coordinated thermogenic response by noradrenaline secretion, suggesting that macrophages secrete cathecholamines to sustain BAT activation.

\section{BAT and the Cardiometabolic Link}

$\nabla$

\section{Cardiac NPs and BAT}

The cardiac natriuretic peptides (NPs) are hormones produced in the heart that serve an important role in hemodynamic and fluid homeostasis. NPs act by binding to NP receptor A (NPRA), which possesses guanylyl cyclase activity, increasing cyclic guanosine monophosphate (GMP) levels and thus activating cyclic GMP-dependent protein kinase (PKG). Another NP receptor (NPRC) is a clearance receptor that removes the NPs from the circulation. These NP actions are parallel to the process of thermogenesis mediated by beta-adrenoreceptors, which act by cyclic AMP-dependent protein kinase (PKA) signaling. Both exert their effect through the $\mathrm{p} 38 \alpha-\mathrm{MAPK}$ pathway, enhancing transcriptional effects. NP receptors are expressed in adipose tissue, and the increase in circulating NPs is associated with lipolysis and weight loss, suggesting a role for NPs as metabolic regulators [107]. A recent novel work by Bordicchia and colleagues demonstrated that atrial NPs and beta-adrenoreceptor agonists can act synergistically to promote adipocyte functions [108]. In both human-derived adipocyte cell lines and mice, cardiac NPs through NPRA and PKG signaling activated p38 $\alpha$-MAPK to increase mitochondrial biogenesis as well as PGC- $1 \alpha$ and UCP1 expression, similar and additive to the response to beta-agonists. NRPC-deficient mice increased the expression of BAT markers, whereas NRPA-deficient mice showed the opposite. Cold exposure increased NP levels, with an increase in the expression of NPRA and a decrease in NPRC, favoring lipolysis and thermogenesis. Furthermore, infusing brain NP into mice stimulated the appearance of brown-like adipocytes, expressing thermogenesis markers in WAT and BAT, associated with increased oxygen consumption and energy expenditure. These results suggest that NPs promote browning of WAT to increase energy expenditure and raise the possibility of achieving greater activation of BAT from an existing level of adrenergic stimulation while avoiding the adverse effects associated with increasing sympathetic nervous tone [109]. Overall, there is increasing recognition that the heart may play an active role in the defense against metabolic diseases.

Studies consistently show an inverse correlation between NP levels and BMI in humans, demonstrating lower levels of NPs in obese individuals. In parallel, there is also a significant inverse correlation between BMI and BAT activity. It is suggested that increased clearance of NPs by NRPC within adipose tissue may have a role in the lower plasma NP levels observed in obese patients. In addition, development of weight loss in patients with advanced heart failure (cardiac cachexia) could be associated with high circulating levels of NPs and catecholamine levels, which may affect the increase in brown fat activity and energy expenditure [108].

\section{Epicardial fat}

Epicardial fat is located between the myocardium and visceral pericardium and shares the same microcirculation of the myocardium. It is active in lipid and energy homeostasis and has endocrine and paracrine effects [110]. In recent years, it was suggested that epicardial fat has a role in the development and progression of atherosclerosis, mediated through oxidative stress and inflammatory signals. Imaging techniques such as echocardiography and CT/MRI can reliably measure epicardial fat thickness, which was shown in several clinical studies to correlate with metabolic syndrome and cardiovascular risk [110112 ] and to be affected by changes in body weight and exercise $[113,114]$. To better understand the thermogenic function of epicardial fat, investigators analyzed fat samples taken during open-heart surgeries in humans with coronary artery disease. They showed that the expression of UCP1 and transcriptional factors marking BAT activity were apparent in epicardial fat in a significantly higher amount compared with other fat depots, raising the possibility that epicardial fat functions like BAT and suggesting that it may have a role in defending the myocardium and coronary vessels from hypothermia [115]. A recent study supported these results, showing an abundance of UCP1 protein in epicardial fat relative to other fat depots and the capability of epicardial fat to alter circulating lipid levels [116].

\section{Lipoprotein metabolism and BAT}

In an obese state, the calories consumed often overpower the ability of the adipose tissue to store lipids, resulting in metabolic and inflammatory derangements leading to ectopic lipid deposition and a risk of developing diabetes. The role of lipoproteins in energy delivery to BAT is not definitely understood. Stimulation of BAT results in efficient uptake of fatty acids and utilization of triglycerides for producing heat. Thus, clearance of triglyceriderich lipoproteins by BAT may protect not only against the cold but also against conditions such as obesity, dyslipidemia, and cardiovascular disease [117]. Indeed, a recent investigation in mice showed that the triglyceride concentration in triglyceriderich lipoproteins was markedly reduced after exposure to cold [118]. Radioactive scans revealed a selective increase in organ uptake of fatty acids into BAT, a process that was facilitated by the transmembrane receptor CD36 and the enzyme lipoprotein lipase. The exposure to cold shifted the clearance of lipoproteins from the liver into BAT. Impaired glucose tolerance was shown in the obese mice and was normalized on exposure to cold. Uptake of triglyceride-rich lipoproteins was independent of insulin levels and resistance. These results support that BAT after exposure to cold regulates triglyceride-rich lipoprotein clearance and is dependent on lipoprotein lipase activity. They also suggest that significant activation of BAT may potentially correct dyslipidemia and improve the metabolic consequences of obesity [119]. Finding ways to increase the mass and activity of BAT may enable promotion of triglyceride clearance and weight loss in order to fight dyslipidemia, obesity, and type 2 diabetes.

\section{Summary and Future Considerations}

$\nabla$

There have been significant advances in recent years in the understanding of the role of BAT in human thermogenesis, uncovering essential knowledge of the origin, differentiation, distribution, activators, and regulation of BAT. The accumulating data suggest that BAT-mediated thermogenesis may be an 
important player in human energy balance. Activating brown fat-mediated thermogenesis may have therapeutic potential in the treatment of patients with obesity, diabetes, and metabolic syndrome, providing new options for interventional therapy. However, parallel to these exciting developments, important issues still need to be solved. Will we find novel ways to stimulate and recruit brown adipocytes and sustain BAT activity? Will targeting BAT thermogenesis be sufficient, tissue specific, and proven safe in humans? How effective and clinically significant will be the recruitment of BAT thermogenesis in reducing obesity and improving insulin resistance, particularly in light of the evidence of reduced mass and activity of BAT in obese individuals? Finally, will physiological compensating and counter-regulatory mechanisms reduce the benefits of BAT activation?

New sites of involvement of BAT, such as epicardial fat, and recognition of novel metabolic influences, such as cardiac NPs, will further contribute to the development and implementation of new perspectives in research on BAT.

\section{Acknowledgements \\ $\nabla$}

I am grateful to Jorge Plutzky M.D., Director of the Vascular Disease Prevention Program, Cardiovascular Division, Brigham \& Women's Hospital, Harvard Medical School, Boston, Massachusetts, for mentoring me through the Cardiometabolic Advanced Fellowship Program, and introducing me to the fascinating field of brown adipose tissue.

\section{Conflict of Interest}

The author declares no potential conflicts of interest with respect to the authorship and/or publication of this article.

\section{References}

1 World Health Organization. Obesity and overweight fact sheet N311. Updated May 2012. Available at http://www.who.int/media centre/factsheets/fs311/en/index.html

2 Cannon B, Nedergaard J. Brown adipose tissue: function and physiological significance. Physiol Rev 2004; 84: 277-359

3 Flegal KM, Carroll MD, Ogden CL, Curtin LR. Prevalence and trends in obesity among US adults, 1999-2008. JAMA 2010; 303: 235-241

4 Nguyen T, Lau DCW. The Obesity Epidemic and Its Impact on Hypertension. Can J Cardiol 2012; 28: 326-333

5 Bays HE. Adiposopathy. Is "sick fat" a cardiovascular disease? J Am Coll Cardiol 2011; 57: 2461-2473

6 Hall KD, Heymsfield SB, Kemnitz JW, Klein S, Schoeller DA, Speakman $J R$. Energy balance and its components: implications for body weight regulation. J Clin Nutr 2012; 95: 989-994

7 Landsberg L, Young JB, Leonard WE, Linsenmeier RA, Turek FW. Do the obese have lower body temperatures? A new look at a forgotten variable in energy balance. Metabolism 2009; 58: 871-876

8 Swinburn BA, Sacks G, Hall KD, McPherson K, Finegood DT, Moodie ML, Gortmaker SL. The global obesity pandemic: shaped by global drivers and local environments. Lancet 2011; 378: 804-814

9 Swinburn B, Sacks G, Ravussin E. Increased food energy supply is more than sufficient to explain the US epidemic of obesity. Am J Clin Nutr 2009; 90: 1453-1456

10 Church TS, Thomas DM, Tudor-Locke C, Katzmarzyk PT, Earnest CP, Rodarte RQ, Martin CK, Blair SN, Bouchard C. Trends over 5 decades in U.S. occupation-related physical activity and their associations with obesity. PLoS One 2011; 6: e19657

11 Hall KD, Sacks G, Chandramohan D, Chow CC, Wang YC, Gortmaker SL, Swinburn BA. Quantification of the effect of energy imbalance on bodyweight. Lancet 2011; 378: 826-837

12 Kraschnewski JL, Boan J, Esposito J, Sherwood NE, Lehman EB, Kephart $D K$, Sciamanna CN. Long-term weight loss maintenance in the United States. Int J Obes (Lond) 2010; 34: 1644-1654
13 Redman LM, Heilbronn LK, Martin CK, de Jonge L, Williamson DA, Delany JP, Ravussin E; Pennington CALERIE Team. Metabolic and behavioral compensations in response to caloric restriction: implication for the maintenance of weight loss. PLoS One 2009; 4: e4377

14 Hill JO, Wyatt HR, Peters JC. Energy balance and obesity. Circulation 2012; 126: 126-132

15 Johnson F, Mavrogianni A, Ucci M, Vidal-Puig A, Wardle J. Could increased time spent in a thermal comfort zone contribute to population increases in obesity? Obesity Rev 2011; 12: 543-551

16 Goodpaster BH, Delany JP, Otto AD, Kuller L, Vockley J, South-Paul JE, Thomas SB, Brown J, McTigue K, Hames KC, Lang W, Jakicic JM. Effects of diet and physical activity interventions on weight loss and cardiometabolic risk factors in severely obese adults: a randomized trial. JAMA 2010; 304: 1795-1802

17 Katan MB, Ludwig DS. Extra calories cause weight gain - but how much? JAMA 2010; 303: 65-66

18 Sjöström L, Peltonen M, Jacobson P, Sjöström CD, Karason $K$, Wedel $H$, Ahlin S, Anveden Å, Bengtsson C, Bergmark G, Bouchard C, Carlsson B, Dahlgren S, Karlsson J, Lindroos AK, Lönroth H, Narbro K, Näslund I, Olbers T, Svensson PA, Carlsson LM. Bariatric surgery and long-term cardiovascular events. JAMA 2012; 307: 56-65

19 Mingrone G, Panunzi S, De Gaetano A, Guidone C, Iaconelli A, Leccesi L, Nanni G, Pomp A, Castagneto M, Ghirlanda G, Rubino F. Bariatric surgery versus conventional medical therapy for type 2 diabetes. $\mathrm{N}$ Engl J Med 2012; 366: 1577-1585

20 Schauer PR, Kashyap SR, Wolski K, Brethauer SA, Kirwan JP, Pothier $C E$, Thomas S, Abood B, Nissen SE, Bhatt DL. Bariatric surgery versus intensive medical therapy in obese patients with diabetes. N Engl J Med 2012; 366: 1567-1576

21 Kozak LP, Koza RA, Anunciado-koza R. Brown fat thermogenesis and body weight regulation in mice: relevance to humans. Int J Obesity 2010; 34: S23-S27

22 Himms-Hagen J. Obesity may be due to a malfunctioning of brown fat. Can Med Assoc J 1979; 21: 1361-1364

23 Heaton JM. The distribution of brown adipose tissue in the human. J Anat 1972; 112: 35-39

24 Huttunen $P$, Hirvonen J, Kinnula $V$. The occurrence of brown adipose tissue in outdoor workers. Eur J Appl Physiol 1981; 46: 339-345

25 Lean ME, James WP, Jennings G, Trayhurn P. Brown adipose tissue in patients with pheochromocytoma. Int J Obes 1986; 10: 219-227

26 Kuji I, Imabayashi E, Minagawa A, Matsuda H, Miyauchi T. Brown adipose tissue demonstrating intense FDG uptake in a patient with a mediastinal pheochromocytoma. Ann Nucl Med 2008; 22: 231-235

27 Wang $Q$ Z Zhang $M$, Ning G, Gu W, Su T, Xu M, Li B, Wang W. Brown adipose tissue in humans is activated by elevated plasma catecholamines levels and is inversely related to central obesity. PLoS One 2011; 6: e21006

28 Engel H, Steinert H, Buck A, Berthold T, Huch Boni RA, von Schulthess GK. Whole Body PET: Physiological and artifactual fluoro-deoxyglucose accumulations. J Nucl Med 1996; 37: 441-446

29 Hany TF, Gharehpapagh E, Kamel EM, Buck A, Himms-hagen J, von Schulthess GK. Brown adipose tissue: a factor to consider in symmetrical tracer uptake in the neck and upper chest region. Eur J Nucl Med Mol Imaging 2002; 29: 1393-1398

30 Cohade C, Osman M, Pannu HK, Wahl RL. Uptake in supraclavivular area fat ("USA fat") description on 18F-FDG PET/CT. J Nucl Med 2003; 44: $170-176$

31 Yeung HW, Grewal RK, Gonen M, Schoder H, Larson SM. Patterns of 18(F)-FDG uptake in adipose tissue and muscle; a potential source of false positives for PET. J Nucl Med 2003; 44: 1789-1796

32 Nedergaard J, Bengtsson T, Cannon B. Unexpected evidence for active brown adipose tissue in adult humans. Am J Physiol Endocrinol Metab 2007; 293: E444-E452

33 Cypess AM, Lehman S, Williams G, Tal I, Rodman D, Goldfine AB, Kuo $F C$, Palmer EL, Tseng YH, Doria A, Kolodny GM, Kahn CR. Identification and importance of brown adipose tissue in adult humans. N Engl J Med 2009; 360: 1509-1517

34 Van Marken Lichtenbelt WD, Vanhommerig JW, Smulders NM, Drossaerts JM, Kemerink GJ, Bouvy ND, Schrauwen P, Teule GJ. Cold activated brown adipose tissue in healthy men. N Engl J Med 2009; 360: 1500-1508

35 Saito M, Okmatsu-Ogura Y, Matsushita M, Watanabe K, Yoneshiro T, Nio-Kobayashi J, Iwanaga T, Miyagawa M, Kameya T, Nakada K, Kawai $Y$, Tsujisaki M. High incidence of metabolically active brown adipose tissue in healthy adult humans: effects of cold exposure and adiposity. Diabetes 2009; 58: 1526-1531

36 Zingaretti MO, Crosta F, Vitali A, Guerrieri M, Frontini A, Cannon B, Needergard J, Cinti S. The presence of UCP1 demonstrates that metabolically active adipose tissue in the neck of adult humans truly represents brown adipose tissue. FASEB J 2009; 23: 3113-3120 
37 Virtanen $K A$, Lidell ME, Orava J, Heglind M, Westergren R, Niemi T, Taittonen M, Laine J, Savisto NJ, Enerback S, Nuutila P. Functional brown adipose tissue in healthy adults. N Engl J Med 2009; 360: 1518-1525

38 Orava J, Nuutila P, Lidell ME, Oikonen V, Noponen T, Viljanen T, Scheinin $M$, Taittonen M, Niemi T, Enerback S, Virtanen KA. Different metabolic responses of human brown adipose tissue to activation by cold and insulin. Cell Metab 2011; 14: 272-279

39 Yoneshiro T, Aita S, Matsushita M, Kameya T, Nakada K, Kawai Y, Saito $M$. Brown adipose tissue, whole-body expenditure, and thermogenesis in healthy adult men. Obesity 2011; 19: 13-16

40 Quellet V, Labbe SM, Blondin DP, Phoenix S, Guerin B, Haman F, Turcotte EE, Richard D, Carpenter AC. Brown adipose tissue oxidative metabolism contributes to energy expenditure during acute cold exposure in humans. J Clin Invest 2012; 122: 545-552

41 Muzik O, Mangner TJ, Granneman JG. Assesment of oxidative metabolism in brown fat using PET imaging. Front Endocrinol (Lausanne) 2012; 15: 1-7

42 Chen YI, Cypess AM, Sass CA, Brownell AL, Jokivarsi KT, Kahn CR, Kwong $K K$. Anatomical and functional assessment of brown adipose tissue by magnetic resonance imaging. Obesity (Silver Spring) 2012; 20: 1519-1526

43 Lee P, Ho KK, Lee P, Greenfield JR, Ho KK, Greenfield JR. Hot fat in a cool man: infrared thermography and brown adipose tissue. Diabetes Obes Metab 2011; 13: 92-93

44 Madar I, Isoda T, Finley P, Angle J, Wahl R. 18F-fluorobenzyl triphenyl phosphonium: a noninvasive sensor of brown adipose tissue thermogenesis. J Nucl Med 2011; 52: 808-814

45 Benchman ES, Dhilon H, Zhang CY, Cinti S, Bianco AC, Kobilka BK, Lowell $B B$. betaAR signaling required for diet-induced thermogenesis and obesity resistance. Science 2002; 297: 843-845

46 Feldman HM, Golozoubova V, Cannon B, Nedergaard J. UCP1 ablation induces obesity and abolishes diet-induced thermogenesis in mice exempt from thermal stress by living at thermoneutrality. Cell Metab 2009; 9: 203-209

47 Vijgen GHEJ, Bouvy ND, Teule GJJ, Brans B, Schrauwen P, Lichtenbelt WDVM. Brown adipose tissue in morbid obese subjects. PloS One 2011; 6: e17247

48 Yoneshiro T, Aita S, Matsushita M, Okamatsu-Ogura Y, Kameya T, Kawai Y, Miyagawa M, Tsujisaki M, Saito M. Age-related decrease in cold-activated brown adipose tissue and accumulation of body fat in healthy humans. Obesity 2011; 19: 1755-1760

49 Vijgen GHEJ, Bouvy ND, Teule GJJ, Brans B, Hoeks J, Schrauwen P, Lichtenbelt WDVM. Increase in brown adipose tissue activity after weight loss in morbid obese subjects. J Clin Endocrinol Metab 2012; 97: 1229-1233

50 Lecoultre $V$, Ravussin E. Brown adipose tissue and aging. Curr Opin Clin Nutr Metab Care 2011; 14: 1-6

51 Lee P, Geenfield JR, Ho KK, Fulham MJ. A critical appraisal of the prevalence and metabolic significance of brown adipose tissue in adult humans. Am J Physiol Endocrinol Metab 2010; 299: E601-E606

52 Pfannenberg C, Werner MK, Ripkens S, Stef I, Deckert A, Schmadl M, Reimond M, Haring HU, Claussen CD, Stefan N. Impact of age on the relationships of brown adipose tissue with sex and adiposity in humans. Diabetes 2010; 59: 1789-1793

53 Au-Yong IT, Thorn N, Ganatra R, Perkins AC, Symonds ME. Brown adipose tissue and seasonal variation in humans. Diabetes 2010; 58 : 2583-2587

54 Rodriguez-Cuenca S, Pujol E, Justo R, Frontera M, Oliver J, Gianotti M, Roca P. Sex-dependent thermogenesis, differences in mitochondrial morphology and function, and adrenergic response in brown adipose tissue. J Biol Chem 2002; 277: 42958-42963

55 Zukotynski KA, Fahey FH, Laffin S, Davis R, Treves ST, Grant FD, Drubach $L A$. Seasonal variation in the effect of constant ambient temperature of 24 degrees $C$ in reducing FDG uptake by brown adipose tissue in children. Eur J Nucl Med Mol Imaging 2010; 37: 1854-1860

56 Hyuang YC, Hsu CC, Wang PW, Chang YH, Chen Tb, Lee FB, Chiu NT. Review analysis of the association between the prevalence of activated BAT and outdoor temperature. Scientific World Journal 2012; 2012: 793039

57 Timmons JA, Wennmalm K, Larsson O, Walden TB, Lassmann T, Petrovic $N$, Hamilton DL, Gimeno RE, Wahlestedt C, Baar K, Nedergarrd J, Cannon $B$. Myogenic gene expression signature establishes that brown and white adipocytes originate from distinct cells lineages. Proc Natl Acad Sci USA 2007; 104: 4401-4406

58 Seale P, Bjork B, Yang W, Kajimura S, Chin S, Kuang S, Scime A, Devarakonda S, Conroe HM, Erdjument-Bromage H, Tempst P, Rudnicki MA, Beier DR, Spiegelman BM. PRDM16 controls a brown fat/skeletal muscle switch. Nature 2008; 454: 961-967
59 Petrovic N, Walden TB, Shabalina IG, Timmons JA, Cannon B, Nedergaard J. Chronic PPARgamma activation of epididymally derived white adipocyte cultures reveals a population of thermogenically competenet, UCP1-containing adipocytes molecularly distinct from classic brown adipocytes. J Biol Chem 2009; 285: 7153-7164

60 Seale P, Kajimura S, Spiegelman BM. Transcriptional control of brown adipocyte development and physiological function - of mice and men. Genes Dev 2009; 23: 788-797

61 Cinti S. Between brown and white: novel aspects of adipocyte differentiation. Ann Med 2011; 43: 104-115

62 Petrovic N, Walden TB, Shabalina IG, Timmons JA, Cannon B, Nedergaard J. Chronic peroxisome proliferator-activated receptor gamma (PPARgamma) activation of epididymally derived white adipocyte cultures reveals a population of thermogenically competent, UCP1containing adipocytes molecularly distinct from classic brown adipocytes. J Biol Chem 2010; 285: 7153-7164

63 Wu J, Bostrom P, Sparks LM, Ye L, Choi Hyun J, Giang AH, Khandekar $M$, Virtanen $K A$, Nuutila $P$, Schaart $G$, Huang $K, T u H$, van Marken Lichtenbelt WD, Hoeks J, Enerbäck S, Schrauwen P, Spiegelman BM. Beige Adipocytes are a distinct type of thermogenic fat cell in mouse and human. Cell 2012; 150: 366-376

64 Sharp LZ, Shinoda K, Ohno H, Scheel DW, Tomoda E, Ruiz L, Hu H, Wang L, Pavlova Z, Gilsanz V, Kajimura S. Human BAT possesses molecular signatures that resemble beige/brite cells. PLoS One 2012; 7: e49452

65 Crisan M, Casteilla L, Lehr L, Carmona M, Paoloni-Giacobino A, Yap S, Sun B, Leger B, Logar A, Pénicaud L, Schrauwen P, Cameron-Smith D, Russell AP, Péault B, Giacobino JP. A reservoir of brown adipocyte progenitors in human skeletal muscle. Stem Cells 2008; 26: 2425-2433

66 Pisani DF, Djedaini M, Beranger GE, Elabd C, Scheideler M, Ailhaud G, Amri EZ. Differentiation of Human Adipose-Derived Stem Cells into "Brite" (Brown-in-White) Adipocytes. Front Endocrinol (Lausanne) 2011; 2: 87

67 Ahfeldt T, Schinzel RT, Lee YK, Hendrickson D, Kaplan A, Lum DH, Camahort R, Xia F, Shay J, Rhee EP, Clish CB, Deo RC, Shen T, Lau FH, Cowley A, Mowrer G, Al-Siddiqi H, Nahrendorf M, Musunuru K, Gerszten RE, Rinn JL, Cowan CA. Programing human pluripotent stem cells into white and brown adipocytes. Nat Cell Biol 2012; 14: 209-219

68 Nishio M, Yoneshiro T, Nakahara M, Suzuki S, Saeki K, Hasegawa M, Kawai Y, Akutsu H, Umezawa A, Yasuda K, Tobe K, Yuo A, Kubota K, Saito $M$, Saeki K. Production of functional classical brown adipocytes from human pluripotent stem cells using specific hemopoietin cocktail without gene transfer. Cell Metab 2012; 16: 394-406

69 Gunawardana SC, Piston DW. Reversal of type 1 diabetes in mice by brown adipose tissue transplant. Diabetes 2012; 61: 674-682

70 Stanford KI, Middelbeek RJ, Townsend KL, An D, Nygaard EB, Hitchcox KM, Markan KR, Nakano K, Hirshman MF, Tseng YH, Goodyear $L J$. Brown adipose tissue regulates glucose homeostasis and insulin sensitivity. J Clin Invest 2013; 123: 215-223

71 Larsen TM, Toubro S, van Baak MA, Gottesdiener KM, Larson P, Saris WH, Astrup A. Effect of a 28-d treatment with L-796568, a novel beta(3)-adrenergic receptor agonist, on energy expenditure and body composition in obese men. Am J Clin Nutr 2002; 76: 780-788

72 Redman LM, de Jonge L, Fang X, Gamlin B, Recker D, Greenway FL, Smith $S R$, Ravussin E. Lack of an effect of a novel beta3-adrenoceptor agonist, TAK-677, on energy metabolism in obese individuals: A doubleblind, placebo-controlled randomized study. J Clin Endocrinol Metab 2007; 92: 527-531

73 Cypess AM, Chen YC, Sze C, Wang K, English J, Chan O, Holman AR, Tal I, Palmer MR, Kolodny GM, Kahn CR. Cold but not sympathomimetics activates human brown adipose tissue in vivo. Proc Natl Acad Sci USA 2012; 109: 10001-10005

74 Carey AL, Formosa MF, Van Every B, Bertovic D, Eikelis N, Lambert GW, Kalff V, Duffy SJ, Cherk MH, Kingwell BA. Ephedrine activates brown adipose tissue in lean but not obese humans. Diabetologia 2013; 56: 147-155

75 Arruda AP, Milanski M, Velloso LA. Hypothalamic inflammation and thermogenesis: the brown adipose tissue connecetion. J Bioenerg Biomembr 2011; 43: 53-58

76 Whittle AJ, Lopez M, Vidal-Puig A. Using brown adipose tissue to treat obesity - the central issue. Trends Mol Med 2011; 17: 405-411

77 López M, Varela L, Vázquez MJ, Rodríguez-Cuenca S, González CR, Velagapudi VR, Morgan DA, Schoenmakers E, Agassandian K, Lage $R$, Martínez de Morentin PB, Tovar S, Nogueiras R, Carling D, Lelliott C, Gallego $R$, Oresic M, Chatterjee K, Saha AK, Rahmouni K, Diéguez C, Vidal-Puig A. Hypothalamic AMPK and fatty acid metabolism mediate thyroid regulation of energy balance. Nat Med 2010; 16: 1001-1008

78 Rothwell NJ, Stock MJ. A role for brown adipose tissue in diet-indued thermogenesis. Obes Res 1997; 5: 650-656 
79 Fromme T, Klingenspor M. Uncoupling protein 1 expression and highfat diets. Am J Physiol Regul Integr Comp Physiol 2011; 300: R1-R8

80 Kozak LP. Brown fat and the myth of diet induced thermogenesis. Cell Metab 2010; 11: 263-267

81 Wijers SL, Saris WH, van Marken Linchtenbelt WD. Individual thermogenic responses to mild cold and overfeeding are closely related. J Clin Endocrinol Metab 2007; 92: 4299-4305

82 Xu X, Ying Z, Cai M, Xu Z, Li Y, Jiang SY, Tzan K, Wang A, Parthasarathy S, He G, Rajagopalan S, Sun $Q$. Exercise ameliorates high-fat diet-induced metabolic and vascular dysfunction, and increases adipocyte progenitor cell population in brown adipose tissue. Am J Physiol Regul Integr Comp Physiol 2011; 300: R1115-R1125

83 De Matteis R, Lucertini F, Guescini M, Polidori E, Zeppa S, Stocchi V, Cinti $S$, Cuppini $R$. Exercise as a new physiological stimulus for brown adipose tissue activity. Nutr Metab Cardiovasc Dis 2012 [Epub ahead of print]

84 Boström P, Wu J, Jedrychowski MP, Korde A, Ye L, Lo JC, Rasbach KA, Boström EA, Choi JH, Long JZ, Kajimura S, Zingaretti MC, Vind BF, Tu $H$, Cinti S, Højlund K, Gygi SP, Spiegelman BM. A PGC1- $\alpha$-dependent myokine that drives brown-fat-like development of white fat and thermogenesis. Nature 2012; 481: 463-468

85 Leone TC, Lehman JJ, Finck BN, Schaeffer PJ, Wende AR, Boudina S, Courtois M, Wozniak DF, Sambandam N, Bernal-Mizrachi C, Chen Z, Holloszy JO, Medeiros DM, Schmidt RE, Saffitz JE, Abel ED, Semenkovich CF, Kelly DP. PGC-1alpha deficiency causes multi-system energy metabolic derangements: muscle dysfunction, abnormal weight control and hepatic steatosis. PLos Biol 2005; 3: e101

86 Uldry M, Yang W, St-Pierre J, Lin J, Seale P, Spiegelman BM. Complementary action of the PGC-1 coactivators in mitochondrial biogenesis and brown fat differentiation. Cell Metab 2006; 3: 333-341

87 Kleiner S, Mepani RJ, Laznik D, Ye L, Jurczak MJ, Jornayvaz FR, Estall JL, Chatterjee Bhowmick D, Shulman GI, Spiegelman BM. Development of insulin resistance in mice lacking PGC- $1 \alpha$ in adipose tissues. Proc Natl Acad Sci USA 2012; 109: 9635-9640

88 Hondares E, Rosell M, Díaz-Delfín J, Olmos $Y$, Monsalve M, Iglesias R, Villarroya $F$, Giralt M. Peroxisome proliferator-activated receptor $\alpha$ $(\mathrm{PPAR} \alpha)$ induces PPAR $\gamma$ coactivator $1 \alpha(\mathrm{PGC}-1 \alpha)$ gene expression and contributes to thermogenic activation of brown fat: involvement of PRDM16. J Biol Chem 2011; 286: 43112-43122

89 Tseng YH, Kokkotou E, Schulz TJ, Huang TL, Winnay JN, Taniguchi CM, Tran TT, Suzuki R, Espinoza DO, Yamamoto Y, Ahrens MJ, Dudley AT, Norris AW, Kulkarni RN, Kahn CR. New role of bone morphogenetic protein 7 in brown adipogenesis and energy expenditure. Nature 2008; 454: 1000-1004

90 Whittle AJ, Carobbio S, Martins L, Slawik M, Hondares E, Vázquez MJ, Morgan D, Csikasz RI, Gallego R, Rodriguez-Cuenca S, Dale M, Virtue $S$, Villarroya F, Cannon B, Rahmouni K, López M, Vidal-Puig A. BMP8B increases brown adipose tissue thermogenesis through both central and peripheral actions. Cell 2012; 149: 871-875

91 Schulz TJ, Huang P, Huang TL, Xue R, McDougall LE, Townsend KL, Cypess AM, Mishina Y, Gussoni E, Tseng YH. Brown-fat paucity due to impaired BMP signaling induces compensatory browning of white fat. Nature 2013; 495: 379-383

92 Cederberg A, Grønning LM, Ahrén B, Taskén K, Carlsson P, Enerbäck S. FOXC2 is a winged helix gene that counteracts obesity, hypertriglyceridemia, and diet-induced insulin resistance. Cell 2001; 106: 563-573

93 Lidell ME, Seifert EL, Westergren R, Heglind M, Gowing A, Sukonina $V$, Arani $Z$, Itkonen $P$, Wallin $S$, Westberg $F$, Fernandez-Rodriguez J, Laakso M, Nilsson T, Peng XR, Harper ME, Enerbäck S. The adipocyteexpressed forkhead transcription factor Foxc2 regulates metabolism through altered mitochondrial function. Diabetes 2011; 60: 427-435

94 Coskun T, Bina HA, Schneider MA, Dunbar JD, Hu CC, Chen Y, Moller $D E$, Kharitonenkov A. Fibroblast growth factor 21 corrects obesity in mice. Endocrinology 2008; 149: 6018-6027

95 Hondares E, Iglesia R, Giralt A, Gonzalez FJ, Giralt M, Mampel T, Villarroya $F$. Thermogenic activation induces FGF21 expression and release in brown adipose tissue. J Biol Chem 2011; 286: 12983-12990

96 Fisher FM, Kleiner S, Douris N, Fox EC, Mepani RJ, Verdeguer F, Wu J, Kharitonenkov A, Flier JS, Maratos-Flier E, Spiegelman BM. FGF21 regulates PGC- $1 \alpha$ and browning of white adipose tissues in adaptive thermogenesis. Genes Dev 2012; 26: 271-281

97 Asano A, Morimatsu M, Nikami H, Yoshida T, Saito M. Adrenergic activation of vascular endothelial growth factor mRNA expression in rat brown adipose tissue: implication in cold-induced angiogenesis. Biochem J 1997; 328: 179-183

98 Elias I, Franckhauser S, Ferré T, Vilà L, Tafuro S, Muñoz S, Roca C, Ramos $D$, Pujol A, Riu E, Ruberte J, Bosch F. Adipose tissue overexpression of vascular endothelial growth factor protects against diet-induced obesity and insulin resistance. Diabetes 2012; 61: 1801-1813
99 Lu X, Ji Y, Zhang L, Zhang Y, Zhang S, An Y, Liu P, Zheng Y. Resistance to Obesity by Repression of VEGF Gene Expression through Induction of Brown-Like Adipocyte Differentiation. Endocrinology 2012; 153: 3123-3132

100 Madsen L, Pedersen LM, Lillefosse HH, Fjaere E, Bronstad I, Hao Q, Petersen RK, Hallenborg P, Ma T, De Matteis R, Araujo P, Mercader J, Bonet ML, Hansen JB, Cannon B, Nedergaard J, Wang J, Cinti S, Voshol $P$, Døskeland SO, Kristiansen K. UCP1 induction during recruitment of brown adipocytes in white adipose tissue is dependent on cyclooxygenase activity. PLoS One 2010; 5: e11391

101 Vegiopoulos A, Müller-Decker K, Strzoda D, Schmitt I, Chichelnitskiy E, Ostertag A, Berriel Diaz M, Rozman J, Hrabe de Angelis M, Nüsing RM, Meyer CW, Wahli W, Klingenspor M, Herzig S. Cyclooxygenase-2 controls energy homeostasis in mice by de novo recruitment of brown adipocytes. Science 2010; 328: 1158-1161

102 Trayhurn P, Drevon CA, Eckel J. Secreted proteins from adipose tissue and skeletal muscle - adipokines, myokines and adipose/muscle cross-talk. Arch Physiol Biochem 2011; 117: 47-56

103 Rhee EJ, Plutzky J. Retinoid metabolism and diabetes mellitus. Diabetes Metab J 2012; 36: 167-180

104 Kiefer FW, Vernochet C, O'Brien P, Spoerl S, Brown JD, Nallamshetty $S$, Zeyda M, Stulnig TM, Cohen DE, Kahn CR, Plutzky J. Retinaldehyde dehydrogenase 1 regulates a thermogenic program in white adipose tissue. Nat Med 2012; 18: 918-925

105 Shapiro H, Lutaty A, Ariel A. Macrophages, meta-inflammation, and immuno-metabolism. Sci World J 2011; 11: 2509-2529

106 Nguyen KD, Qiu Y, Cui X, Goh YP, Mwangi J, David T, Mukundan L, Brombacher F, Locksley RM, Chawla A. Alternatively activated macrophages produce catecholamines to sustain adaptive thermogenesis. Nature 2011; 480: 104-108

107 Wang TJ. The natriuretic peptides and fat metabolism. N Engl J Med 2012; 367: 377-378

108 Bordicchia M, Liu D, Amri EZ, Ailhaud G, Dessì-Fulgheri P, Zhang C, Takahashi N, Sarzani R, Collins S. Cardiac natriuretic peptides act via p38 MAPK to induce the brown fat thermogenic program in mouse and human adipocytes. J Clin Invest 2012; 122: 1022-1036

109 Whittle AJ, Vidal-Puig A. NPs - heart hormones that regulate brown fat? J Clin Invest 2012; 122: 804-807

110 Iacobellis $G$, Malavazos AE, Cordi MM. Epicardial fat: from the biomolecular aspects to the clinical practice. Int J Biochem Cell Biol 2011; 43: 1051-1054

111 Iacobellis G, Lonn E, Lamy A, Singh N, Sharma AM. Epicardial fat thickness and CAD correlate independently of obesity. Int J Cardiol 2011; 146: 452-454

112 De Vos AM, Prokop M, Roos CJ, Meijs MFL, Van der Schouw YT, Rutten A, Gorter PM, Cramer MJ, Doevendans PA, Rensing BJ, Bartelink ML, Velthuis BK, Mosterd A, Bots ML. Peri-coronary epicardial adipose tissue is related to cardiovascular risk factors and coronary artery calcification in post-menopausal women. Eur Heart J 2008; 29: 777-783

113 Iacobellis $G$, Singh $N$, Wharton S, Sharma AM. Substantial changes in epicardial fat thickness after weight loss in severely obese subjects. Obesity 2008; 16: 1693-1697

114 Kim MK, Tomita T, Kim MJ, Sasai H, Maeda S, Tanaka K. Aerobic exercise training reduces epicardial fat in obese men. J Appl Physiol 2009; 106: 5-11

115 Sacks HS, Fain JN, Holman B, Cheema P, Chary A, Parks F, Karas J, Optican R, Bahouth SW, Garrett E, Wolf RY, Carter RA, Robbins T, Wolford D, Samaha J. Uncoupling protein-1 and related messenger ribonucleic acids in human epicardial and other adipose tissues: Epicardial fat functioning as brown fat. J Clin Endocrinol Metab 2009; 94: 3611-3615

116 Chechi K, Blanchard PG, Mathieu P, Deshaies Y, Richards D. Brown fat like gene expression in the epicardial fat depot correlates with circulating HDL-cholesterol and triglycerides in patients with coronary artery disease. Int J Cardiol 2012 [Epub ahead of print]

117 Williams KJ, Fisher EA. Globular warming: how fat gets the furnace. Nat Med 2011; 17: 157-159

118 Bartlet A, Bruns OT, Reimer R, Hohenberg H, Ittrich H, Peldschus $K$ Kaul MG, Tromsdorf UI, Weller H, Waurisch C, Eychmüller A, Gordts $P L$, Rinninger F, Bruegelmann K, Freund B, Nielsen P, Merkel M, Heeren $J$. Brown adipose tissue activity controls triglyceride clearance. Nat Med 2011; 17: 200-205

119 Bartlet A, Merkel M, Heeren J. A new, powerful player in lipoprotein metabolism: brown adipose tissue. J Mol Med 2012; 90: 887-893 